\section{Gravidez e comportamento alimentar em gestantes de uma comunidade urbana de baixa renda no Município do Rio de Janeiro, Brasil}

\author{
Pregnancy and eating behavior in pregnant women \\ from a low-income neighborhood in \\ Rio de Janeiro, Brazil
}

\author{
${ }^{1}$ Instituto de Nutrição Josué \\ de Castro, Universidade \\ Federal do Rio de Janeiro, Rio \\ de Janeiro, Brasil. \\ 2 Instituto Fernandes \\ Figueira, Fundação Oswaldo \\ Cruz, Rio de Janeiro, Brasil. \\ Correspondência \\ M. R. Baião \\ Instituto de Nutrição Josué de \\ Castro, Universidade Federal \\ do Rio de Janeiro. \\ Av. Brigadeiro Trompowsky \\ $s / n^{\circ}$., Centro de Ciências da \\ Saúde, Bloco 1, 2o andar, \\ Rio de Janeiro, $R J$ \\ 21941-590, Brasil. \\ mirianbaiao@uol.com.br
}

\section{Abstract}

The aim of this study was to understand the meanings of acceptance attributed to pregnancy and their influence on the eating behavior of pregnant women attending a health unit located in a low-income neighborhood in the city of Rio de Janeiro, Brazil. The methodology involved a qualitative approach with social representations as the analytical category. Data were collected through semi-structured interviews with adolescent and adult pregnant women (primiparous or multiparous) in different stages of pregnancy. Discourse analysis drew on in-depth hermeneutics, using thematic analysis as the main technical resource. Two representational categories emerged from the set of discourses, namely accepting versus not accepting the pregnancy, which involved different eating behaviors. In the former, women tended to either eat adequately or overeat. For the latter, not accepting the pregnancy was associated with denial of eating, temporarily or throughout the pregnancy.

Pregnancy; Feeding Behavior; Qualitative Research
Mirian Ribeiro Baião ${ }^{1}$

Suely Ferreira Deslandes 2

\section{Introdução}

A gestação é um período marcado por inúmeras mudanças. As imediatamente reconhecidas são as relacionadas ao corpo, em decorrência das demandas fisiológicas desse evento. A confirmação da condição de estar grávida também gera expectativa de intensos cuidados e investimentos sobre a criança que vai nascer ${ }^{1}$ e para os quais, algumas mulheres, podem não se sentir preparadas, material e emocionalmente, para enfrentar. Diante de todas as modificações possíveis de ocorrer, o potencial de influência de uma gravidez sobre a subjetividade da mulher nem sempre é previsível.

Com relação à alimentação durante a gestação, o conhecimento científico aponta que as necessidades nutricionais aumentam, sendo recomendadas alterações na dieta 2 com vistas à saúde do binômio mãe-filho.

No Brasil, pesquisas que investigam o tema alimentação na gestação priorizam metodologias quantitativas com objetivo de avaliar o estado nutricional materno, o ganho de peso gestacional e a associação com variáveis de interesse 3,4,5. De forma menos constante, alguns estudos incorporam o conhecimento das crenças, proibições e prescrições que interferem no comportamento e nas práticas alimentares de gestantes, puérperas e lactantes 6,7,8.

Para uma grávida, o ato de comer pode ser intensamente afetado por questões objetivas, 
como os recursos materiais disponíveis, que interferem na disponibilidade e no acesso aos alimentos, as condições sociais e as experiências corpóreas (ganho de peso, enjôos, vômitos etc.). Entretanto, a própria gravidez pode adquirir para as mulheres sentidos ligados à imagem corporal, aos significados atribuídos à saúde e à doença, à maternidade, ao discurso médico, entre outros aspectos que também influenciam no comportamento alimentar das gestantes 9 . Tais sentidos são construídos e reconstruídos com base em valores, discursos, crenças, emoções e na experiência cotidiana 10 .

Este estudo parte do pressuposto de que a ação dos sujeitos é sempre motivada, sendo o motivo uma conexão de sentidos que se constitui enquanto principal razão de uma determinada ação ${ }^{11}$. Desse modo, a interpretação de uma ação social dar-se-á quando o desenrolar externo, os sentidos forem conhecidos e, ao mesmo tempo, compreensíveis quanto aos seus nexos 11,12. Porém, dificilmente tais sentidos serão totalmente compreendidos, dado que incluem motivações dinâmicas e também relacionadas à ordem biográfica e psíquica de fenômenos.

A análise dos nexos de sentidos entre a gravidez e o comportamento alimentar das mulheres que participaram da investigação tomou como base a discussão de cunho antropológico, realizada por Leal \& Lewgoy ${ }^{13}$. Os autores defendem que "assumir ou não a gravidez" são situações eminentemente relacionadas a um "dever" e um "poder" de gerar e criar uma criança. Para eles, enquanto a gravidez não for, de fato, "assumida" pela mulher, não há o reconhecimento de uma criança em formação. O "assumir" torna a gravidez legítima do ponto de vista social, e uma série de condições e adequações morais, emocionais e materiais, seja com o companheiro, familiares ou outros sujeitos significativos, respaldam essa decisão 13 .

$\mathrm{Na}$ literatura científica encontram-se trabalhos que discutem a gravidez planejada e a desejada e seus opostos, mas essas categorias são associadas a questões anteriores à concepção, como falhas ou uso incorreto de contraceptivos, imposição de relações sexuais, bem como projetos de emancipação e outros 14,15. A opção pela adoção da categoria "assumir", empregada por Leal \& Lewgoy 13 (p. 65), ocorreu por designar um conjunto de "arranjos e negociações sociais que são efetivamente acionados pós-concepção biológica" e também por ser a mais próxima das expressões êmicas enunciadas pelas mulheres deste estudo para revelar os processos de aceitação da gravidez.

Com base nessa reflexão, a pesquisa teve como objetivo compreender os sentidos de acei- tação atribuídos à gravidez e como eles influenciam no comportamento alimentar de mulheres que vivem em uma comunidade de baixa renda no Município do Rio de Janeiro, Brasil.

\section{Metodologia}

O presente estudo foi conduzido pela abordagem qualitativa no campo analítico das Representações Sociais.

As representações sociais são um tipo de saber socialmente negociado, contido no senso comum e no cotidiano 16 , forjadas no contexto de determinada realidade sócio-histórica, ao mesmo tempo em que contribuem para sua construção 17,18.

Apesar de amplamente empregada em estudos na área da saúde que adotam a metodologia qualitativa, as representações sociais têm sido alvo de reflexões críticas 16,18. Para Herzlich 18, na maioria das vezes, se concebe uma ligação mecânica entre as representações e as ações individuais específicas. Assim como Herzlich 18, Alves \& Rabelo 19 se colocam contrários à visão de determinação das representações sobre as práticas em saúde e doença e apresentam o conceito de experiência como um campo no qual se entrecruzam as dimensões das representações e das práticas, por conseguinte, um caminho para superação das dicotomias existentes.

De maneira similar ao processo saúde-doença, o fenômeno social alimentar igualmente se manifesta pelo pólo representacional e pelo pólo das ações. Contudo, as contradições, ambigüidades e dilemas existentes nos remetem a reconhecer a interação dialética que se faz presente entre os pensamentos, comportamentos e práticas alimentares dos sujeitos e grupos sociais.

Neste estudo, as falas das gestantes entrevistadas possibilitaram conhecer os "dados de representação" e os "dados comportamentais" 20. Evitou-se cair na armadilha de tomá-los como dimensões estanques do mesmo fenômeno.

A noção de comportamento alimentar foi utilizada para expressar as ações dos sujeitos, socialmente situados, relacionadas ao ato de comer. Foram valorizados aspectos subjetivos como os sentidos e valores atribuídos à alimentação e à gestação e os motivos que desencadeavam o comportamento alimentar.

De acordo com os pressupostos da perspectiva qualitativa não foi prevista uma amostragem a priori. Adotou-se o critério de saturação das falas ${ }^{21}$ para definição do número de mulheres grávidas que fizeram parte da pesquisa, tendo sido incluídas seis gestantes adolescentes e 12 adultas. 
Reconhece-se que, na adolescência, a gravidez pode ter motivações e repercussões distintas de uma mulher adulta 22 . Assim, justamente a fim de possibilitar os contrastes e alcançar a maior abrangência dos sentidos atribuídos à gravidez e à alimentação, procurou-se contemplar a diversidade dos sujeitos e de seu campo de experiências, tendo sido entrevistadas mulheres grávidas em diferentes idades, distintos períodos de gestação, primíparas e multíparas. Estas peculiaridades foram pontuadas apenas quando as diferenças se fizeram notar.

Todas as gestantes que participaram do estudo viviam no Complexo de Manguinhos, no Rio de Janeiro. A captação ocorreu em uma unidade básica de saúde da área, no ano de 2005, e o tempo destinado à coleta de dados foi em torno de quatro meses.

O projeto de pesquisa foi aprovado por Comitê de Ética e todas as gestantes assinaram o Termo de Consentimento Livre e Esclarecido.

Empregou-se como técnica de construção de dados a entrevista em profundidade do tipo semi-estruturada, que abordou os seguintes eixos temáticos: a gravidez; saúde, comportamento e práticas alimentares e discursos sobre alimentação na gravidez.

Inicialmente, a gestante era abordada pela pesquisadora nas salas de espera da unidade de saúde. A entrevista era gravada e realizada pela autora principal, em espaços isolados de atendimento, sendo conduzida de forma a garantir a privacidade dos sujeitos. O encontro com cada mulher durou, em média, de duas a três horas. Após cada entrevista, os eventos ocorridos, as expressões e os gestos das entrevistadas; sentimentos, impressões e observações da pesquisadora eram narrados, sob forma de registro escrito, para complementar as falas e subsidiar a análise de conteúdo do conjunto dos depoimentos. O interesse das mulheres naquela conversa e a intimidade alcançada entre a pesquisadora e as entrevistadas possibilitaram o aprofundamento dos temas. O momento da entrevista proporcionou às mulheres o distanciamento de seu cotidiano e possibilidade de reflexão sobre o mesmo 23 .

Todas as gravações foram transcritas textualmente pela pesquisadora, de forma fidedigna, registrando-se as falas, entonações de voz, interjeições, silêncios, ou seja, os códigos verbais e não verbais, de acordo com a análise que se desejava realizar.

O processo de análise e interpretação das falas foi inspirado nas orientações da Hermenêutica de Profundidade, proposta por Thompson 24, que engloba três fases, as quais não necessariamente ocorrem de maneira linear.
A primeira fase, a análise "sócio-histórica", teve como finalidade reconstruir as condições de produção, circulação e recepção das formas simbólicas (ações, falas e textos), vale dizer, buscouse conhecer a estrutura social, a história dos sujeitos e da comunidade, as relações entre as pessoas, as normas, seus ajustes e flexibilizações.

A "análise formal ou discursiva" correspondeu à análise propriamente dita. Seu principal objetivo foi organizar o material empírico e identificar características estruturais internas das falas, seus padrões e relações. Thompson 24 deixa claro que existem várias maneiras de se conduzir esta análise, que depende do objeto e das circunstâncias particulares da investigação. O estudo se valeu de uma adaptação da análise de conteúdo em sua vertente temática 25,26. Esta fase foi organizada em duas etapas: "pré-análise" e "exploração do material". Na "pré-análise" realizou-se a leitura "flutuante", constituição das corpora de análise, formulação de hipóteses e objetivos iniciais 25 . Durante a etapa de "exploração" do material, procedeu-se à codificação, quando foram identificados os "núcleos de sentido" e implementada a categorização 25. Em princípio, a análise privilegiou as categorias êmicas para posteriormente promover o diálogo destas com as categorias analíticas do estudo.

A fase de "interpretação e reinterpretação" significou um movimento novo do pensamento a que se procedeu por meio de inferências elaboradas mediante síntese, insights e confronto com a literatura 24 .

\section{Resultados e discussão}

\section{O cenário da pesquisa e a caracterização das} gestantes: o contexto de produção das representações

Com a pretensão de descrever o contexto social onde se inserem as gestantes e se localiza seu campo de vivências, apresentam-se as condições da comunidade onde viviam e algumas características do grupo.

A população de Manguinhos é de, aproximadamente, 54 mil habitantes. Destes, $52 \%$ são mulheres, $48 \%$, homens, e $54 \%$ se encontram na faixa etária de 15-49 anos 27. Existem cerca de 12 mil domicílios, sendo 30\% em áreas irregulares ou de risco, com ocupação de 3,7 moradores, em média, por domicílio 27 . Dentre crianças e adolescentes de 5-14 anos, 15\% estão fora da escola. Há total ausência de estabelecimentos públicos com oferta de ensino a partir da quarta série 27 . Da população economicamente ativa, $45 \%$ estão no mercado informal, com precariedade do tra- 
balho devido ao subemprego e desemprego 27 . O tráfico de drogas está por trás de $30 \%$ das mortes na região ${ }^{28}$. Em síntese, tais dados configuram uma realidade de pobreza, exclusão social e insuficiente cobertura das políticas públicas promotoras de cidadania.

Com relação às características dos sujeitos, a idade variou de 15-33 anos; apenas seis mulheres tinham alguma atividade remunerada fora do lar (faxineira, secretária, costureira, recreadora e empregada doméstica) e a maioria (11) não completou o Ensino Fundamental. Ainda que o grupo fosse formado por adolescentes e adultas jovens, somente duas gestantes se mantinham estudando na época da entrevista. As demais já tinham interrompido a educação formal muito antes de saberem que estavam grávidas.

Do conjunto, dez eram primíparas e 13 viviam com o marido ou companheiro. Destas, dez permaneciam unidas ao primeiro cônjuge. Embora não tenha sido observada a instabilidade conjugal, as que estavam vivendo maritalmente se queixaram de seus companheiros, especialmente porque eles não tinham remuneração certa, ganhavam pouco ("mal dá para comer") ou não estavam trabalhando. Somado a isso, havia o "gasto com bebida", um comportamento masculino reprovável para as mulheres e, ainda, maridos que "seguravam" o dinheiro. As gestantes também revelaram sentir solidão, sensação de "enjôo" dos parceiros e o distanciamento da parte deles. Assim, a gravidez podia ser mais um problema a ser enfrentado ou negociado nos freqüentes relacionamentos conjugais conflituosos num contexto de dificuldades sócio-econômicas.

O perfil sócio-demográfico apresentado retrata a realidade já conhecida sobre a vida das mulheres que moram em áreas urbanas mais pobres. Elas enfrentam o difícil acesso à educação, as poucas oportunidades de trabalho e o trabalho desqualificado, a gravidez na adolescência, a "gravidez não assumida" e, muitas vezes, a responsabilidade total pela criação dos filhos. Este quadro é corroborado por Bourdieu 29 ao apontar que as mulheres são mais atingidas pelo desemprego e pelo trabalho precário e relegadas, com mais facilidade, a cargos desqualificados, levando, entre os muitos efeitos, à sua exclusão dos jogos de poder e das perspectivas de carreira, fazendo delas as maiores vítimas do neoliberalismo.

\section{A gravidez e o modo como as mulheres se alimentavam}

Das gestantes que participaram deste estudo, algumas relataram que já tinham a intenção de engravidar e, em contrapartida, outras manifes- taram inconformismo com o fato. Somente duas mulheres "assumiram a gravidez" tão logo foi confirmada, ainda que tenham admitido não têla planejado.

Certas condições/situações, reunidas ou não, favoreceram a aceitação da gravidez desde o seu início para algumas entrevistadas. Para outras, a decisão de "assumir" veio com o tempo. Havia aquelas que, no entanto, permaneciam inconformadas com o evento ao longo do seu percurso.

Uma das questões mais significativas para "assumir a gravidez" dizia respeito ao fato de a mulher ou o casal ainda não ter filhos ou não estar vivendo com os filhos (quando as crianças eram criadas por outras pessoas). Essa era uma situação reconhecida como mais propícia ao nascimento de uma criança, particularmente do ponto de vista sócio-econômico, uma vez que um número maior de filhos aumentava as dificuldades da família.

O trabalho de carteira assinada, da mulher e/ou de seu companheiro, significava certa estabilidade financeira e segurança, o que dava mais tranqüilidade à chegada de um bebê.

O apoio da mãe, da família e do companheiro que, segundo Leal \& Lewgoy 13 também precisam "assumir a gravidez", foi colocado como uma condição importante que favoreceu a aceitação pela gestante.

A religião apareceu como mais um elemento que contribuiu para que uma das mulheres se resignasse com o fato de estar grávida. Mesmo não sendo a sua vontade, era a vontade de Deus se materializando e contra essa ninguém teria o poder de se opor.

O temor de praticar aborto e das conseqüências desse ato foi mais forte do que o medo de ter que enfrentar a gravidez e "assumir" mais um filho para algumas das entrevistadas.

As mulheres que "assumiram a gravidez" revelaram dois tipos possíveis de comportamento alimentar, dualmente caracterizado por elas como "bom", pautado por uma "alimentação saudável" ou "ruim", quando adotavam uma "má alimentação".

A "alimentação saudável" foi significada de maneira positiva pela associação com a saúde materna e com o crescimento e desenvolvimento do bebê, sendo, por esses motivos, necessária. Já a "má alimentação", apontada como uma possível causa de "doenças", estava especialmente associada ao exagero no consumo alimentar e excessivo aumento de peso.

“... Aumentei muito o meu peso (...) foram uns nove (...) quase dez quilos que eu engordei num mês só, porque eu comi muito, eu exagerei. (...) $O$ normal seria (...) eu ter engordado esses nove quilos na gravidez toda (...) se todo mês eu engordar 
isso, vou ter sérios problemas, né?" (G14; quatro meses de gravidez).

O aumento exagerado do peso sinalizava um risco eminente de adoecer, ou até morrer, e impunha necessidade de mudanças no comportamento alimentar. Mas se era difícil controlar a vontade de comer e fazer dieta, para uma grávida se tornava pior do que para qualquer outra pessoa. A dificuldade para aderir à dieta era justificada pela insipidez das preparações e pela "fome" exagerada que sentiam.

Por outro lado, entre as mulheres que afirmaram não se sentirem preparadas para "assumir a gravidez", todas interpretaram e nomearam o seu comportamento alimentar com expressões negativas em função da pouca ou nenhuma vontade de comer.

“A alimentação está ruim porque eu não estou sentindo vontade de comer. Tô com fastio. Pra falar a verdade, eu fiquei um pouco (...) [pausa] eu não queria, não. Até tomar remédio pra tirar, eu tomei [pausa - baixou a cabeça]" (G7; seis meses de gravidez).

Essa forma de comportamento podia acontecer temporariamente ou até se estender por toda a gestação, e uma seqüência de eventos acometia as mulheres que a admitiram, sobretudo nos primeiros meses. A confirmação da gravidez podia desencadear insatisfação, tristeza, depressão, náuseas e vômitos freqüentes e intensos, pouco ou nenhum estímulo para comer e perda de peso, às vezes, acentuada, conforme pode ser observado na fala abaixo.

“... Estou mais magra, perdi muito peso, porque eu não conseguia comer. Eu sentia enjôo, vontade de vomitar (...) tudo que eu comia, botava pra fora. Agora melhorou um pouco. De dois meses pra cá, que eu estou conseguindo me alimentar. Mas eu fiquei bastante tempo sem me alimentar (...). Nem água, eu não conseguia beber. Agora, eu acho que foi porque eu entrei, assim, em depressão, né? Porque eu fiquei muito (...) eu não queria, então, eu fiquei muito depressiva. Aí, eu não conseguia comer [baixou os olhos com tristeza]" (G8 - sete meses de gravidez).

Todavia, neste grupo, algumas gestantes revelaram que mudaram, por volta do quinto mês, o que interpretavam como um comportamento "ruim" para um "mais normal". Apreenderam-se "núcleos de sentido" que denotam essa mudança. Após o impacto inicial, transcorrido o primeiro trimestre, no decorrer do segundo, quando a barriga crescia e o feto começava a mexer, iniciava-se um processo de conformação 22. Em outros termos, a partir do momento em que as alterações corporais se tornavam mais intensas e os sinais do bebê eram percebidos pelas mulheres, ocorria a aceitação da gravidez.
Para uma dessas gestantes, um episódio foi marcante. Aos cinco meses, a ultra-sonografia revelou que "o bebê estava só com duzentas gramas” (G15). A constatação a impressionou e a motivou a comer mais, sem que ninguém tenha influenciado em sua decisão.

Como visto em outros estudos 1 , a imagem revelada no exame mostrou a integralidade do bebê e transformou a criança a nascer num ser real, aproximando os modelos explicativos da gestante com os do discurso médico. Ao interpretar que o bebê estava "magrinho", ela imediatamente associou o fato ao seu comportamento alimentar e elaborou a idéia de risco e culpa.

Observou-se empiricamente uma tendência no consumo alimentar dessas gestantes. Até cerca dos cinco primeiros meses o consumo alimentar era insuficiente, aos seis e sete meses aumentou e, aos oito meses, elas revelaram que passaram a comer muito.

A mudança no comportamento alimentar coincidiu com os diferentes significados atribuídos à gravidez. Inicialmente um choque, uma luta interna entre o querer, o dever e o poder, um problema a ser resolvido. Depois, uma situação que começa a ser "arranjada" subjetivamente e nos contextos sócio-econômico e familiar, até começar a ser "assumida”. Finalmente, reorganizam-se as representações sociais da relação da alimentação com a saúde na gestação. Nesse sentido, tal mudança era acompanhada de um despertar das gestantes para o cuidado com a saúde, particularmente a do bebê. Pode-se dizer que essa conduta também significava uma forma de superação da culpa ocasionada pela atitude anterior, que acabava por desencadear numa alimentação inadequada para o crescimento e desenvolvimento da criança durante a gestação.

A partir do momento em que a gravidez foi ressignificada como uma condição positiva, ela passou a ser "assumida". O fato interferiu no ato de comer e favoreceu o aumento no consumo, que, no senso comum, pode ser considerado normal, pois conforme dito por algumas mulheres, "a grávida tem que comer mais e comer tudo que tem vontade".

Com isso, o último trimestre de gravidez foi marcado por um ganho de peso insatisfatório, sob o ponto de vista dessas mulheres, trazendo à tona o fantasma da obesidade. Logo, para elas, o "assumir a gravidez" também implicou exageros alimentares.

\section{O contexto das gestantes que se negavam a comer}

A negação do ato de comer podia ser desencadeada pela gravidez ou reforçada por ela quando 
outras situações já causavam algum tipo de sofrimento à mulher.

Conforme citado anteriormente, o fato de já ter filhos era algo que pesava negativamente na decisão das mulheres de levar aquela gravidez adiante, agravando a falta de interesse pela comida. A dificuldade financeira comprometia a criação dos filhos, mormente quando a família vivia em situação de insegurança alimentar, caracterizada, no grupo, pelo difícil ou quase inexistente acesso aos alimentos.

Os problemas de relacionamento enfrentados por tais gestantes com seus companheiros e/ou familiares também as deixavam muito vulneráveis. As relações conflituosas traziam instabilidade, insegurança, medo e sofrimento porque as mulheres não tinham perspectiva de romper, em curto prazo, com as situações a que estavam expostas e o futuro se tornava incerto. A fim de compreender esta problemática, buscou-se a discussão desenvolvida por Hita 30 sobre "conflito" e "crise". Apoiada no referencial da Antropologia Médica e da Sociologia da Saúde, a autora explica que o "conflito" tanto pode servir para impulsionar o indivíduo como pode culminar numa situação "paralisadora", levando a uma "crise" que se manifesta por "um movimento de entrega e rendição" frente ao "conflito", pela "fragilização", pela "quebra do equilíbrio" e por "sentimentos de padecimento" 30 (p. 181). No caso da mulher, parece haver situações que estão relacionadas às diferenças de gênero com "conflitos" que podem se transformar em "crise" 30, desencadeando comportamentos autodestrutivos e até em formas específicas de adoecer como revelado nas falas e expressões das gestantes deste estudo.

Fumar e/ou usar droga foram comportamentos relatados por gestantes com pouco ou nenhum estímulo para comer. Estas eram mulheres nas quais se evidenciava negligência com a aparência, debilidade física e emocional. Ao contrário, mulheres que "assumiram a gravidez" referiram que, após a sua confirmação, pararam de fumar, revelando adesão às orientações antitabagistas comuns no pré-natal.

Enjôos e vômitos também foram apontados como motivo para não comer, causa da perda de peso e de sofrimento. As gestantes associavam esses sintomas ao fato de terem ficado deprimidas com a gravidez, sendo muito mais freqüentes e intensos que o normal. A intensidade, gravidade e freqüência dos vômitos, conforme relatado, sugeriam um pensamento pré-reflexivo de "jogar para fora, expelir” aquela gravidez, como observado por Leal 31 .

No grupo que "assumiu a gravidez" desde o início e que estava se alimentando, segundo elas, de maneira "boa", também houve as que experimentaram enjôos e vômitos, situação que, poucas vezes, comprometeu a ingestão alimentar, semelhante ao estudo de Rito ${ }^{32}$. Nestes casos, não foi dada importância a esses sintomas, para os quais era atribuído o sentido de uma coisa "normal" para uma mulher grávida, embora tidos como desagradáveis.

Chamou atenção o relato de uma das mulheres entrevistadas. Aos cinco meses estava realizando a segunda consulta de pré-natal porque havia perdido o "cartão do posto". Continuava fumando, comendo pouco, ou quase nada, e visivelmente sofria de magreza acentuada. A mesma acreditava que o fato de comer contribuía com o crescimento da criança e, se o bebê fosse grande, ela poderia não ter forças para expulsá-lo no parto. Contou que na gravidez anterior tal fato aconteceu, causando enorme sofrimento, mesmo tendo evitado comer porque, na época, não queria engordar.

“...Da minha outra filha (...) tinha vezes que eu ficava com aquele negócio tipo [pausa] querendo ficar magra. Aí, teve uma época que eu parei de comer (...). Eu via eu magrinha, só com um barrigão. Aí, fui secando, secando, secando (...) eu queria ficar mais magra por causa da barriga (...). Tive anemia profunda, tive que fazer quatro curetagens e me deram quatro tubos de sangue quando eu tive ela. Nasceu viva. Ela não teve problema nenhum, só eu" (G6; cinco meses de gravidez - história da gravidez anterior).

Como demonstrado na fala desta gestante, algumas mulheres podem diminuir demais a ingestão de alimentos, podendo levar à desnutrição e à distorção da imagem corporal, com conseqüente medo de engordar e desejo de manterse cada vez mais magra 33. Para esta entrevistada, tal situação não estava descartada.

A história desta mulher pode ser considerada emblemática em razão de sua total vulnerabilidade. As precárias condições sócio-econômicas (dificuldade para ler e escrever, renda familiar insuficiente, condições de moradia precárias, filhos menores de cinco anos etc.) deveriam ter sido suficientes para que ela fosse assistida com prioridade. As questões relacionadas à subjetividade tornavam ainda mais complexa sua situação, merecendo ambas serem consideradas na assistência, visando tanto à proteção da saúde quanto à social.

\section{A "negação do ato de comer": uma estratégia} de aborto não assumida?

Para Leal \& Lewgoy 13, o "assumir a gravidez" é uma condição relacional diante de um conjunto de itens que deve ser "harmônico". Se este con- 
junto não estiver presente pode tornar tolerável o aborto.

Sabe-se que o aborto, no Brasil, tem taxas alarmantes. Moteiro \& Adesse ${ }^{34}$ estimaram que, no período de 1992-2005, o número de abortos induzidos caiu de 1.455.283 para 1.054.242. Em 1992, a proporção de abortos equivalia a $43 \%$ dos nascimentos vivos e, em 2005, essa proporção caiu para $30 \%$. Apesar da redução de abortamentos, para os autores, a anticoncepção no país ainda não atingiu as mulheres de maneira a evitar gravidezes indesejadas.

É possível cogitar também que, em função de questões morais e religiosas, muitas mulheres pratiquem estratégias abortivas que nem sempre são assumidas como tais. Por exemplo, o uso dos chás, para “descer a menstruação", não é uma prática imediatamente identificada como abortiva, se a gravidez ainda não tiver sido reconhecida socialmente 13,31 .

Nas falas das mulheres entrevistadas, a palavra aborto foi freqüentemente substituída pelo termo "tirar", como também referido por Leal 31. Desse jeito, o tema foi trazido, explicitamente, por gestantes que haviam provocado esse ato naquela gravidez e, na visão delas, não tinham tido sucesso e por aquelas que, de alguma forma, se sentiam envolvidas com o assunto, por mais que não o tenham praticado por motivos religiosos e por medo ou trauma.

Despertou interesse o método empregado para realização do aborto. A prática de utilização do Cytotec (Pfizer), comercializado ilegalmente para essa finalidade, era difundida entre as mulheres. Todavia, no Brasil, esse medicamento só pode ser vendido para hospitais 35 . As gestantes precisavam fazer um grande esforço para comprar o produto. Cada comprimido custava, em média, 35 Reais, sendo necessários quatro, de uma única vez (dois ingeridos por via oral e dois introduzidos na vagina). Para as entrevistadas, a restrição à venda e a dificuldade para adquirir o remédio davam idéia de que esse é mesmo eficaz no seu efeito abortivo, fato também observado por Leal ${ }^{31}$.

Durante as entrevistas percebeu-se que, embora inicialmente não estivesse contemplado em nenhum dos objetivos da pesquisa, o aborto não poderia ficar à margem da interpretação, tendo sido compreendida a sua associação com o objeto deste estudo.

Uma "gravidez não assumida” pode significar um enorme problema para muitas mulheres, independente da idade, situação conjugal e nível de renda, desencadeando sentimentos de angústia, medo e raiva. Mas, para mulheres de classes pobres, o problema se torna mais complexo. As situações de escassez de recursos corroboram para agravar os sentidos negativos em relação à gravidez.

A decisão de abortar era conflituosa, especialmente porque a gestante se sentia pressionada, por razões distintas, mas todas as conseqüências da realização ou não do aborto só seriam experimentadas pela própria mulher, que acabava tendo de assumir sozinha a responsabilidade.

Para algumas, era extremamente difícil admitir o aborto intencionalmente provocado. Parecia menos traumático, por não imputar em culpa, a interrupção da gravidez por uma causa aparentemente natural. Nesse sentido, a atitude de negligenciar o ato de comer poderia contribuir, inviabilizando a gestação.

A intenção de negação do ato de comer enquanto uma estratégia abortiva não foi declarada de maneira explícita nas falas das mulheres. Contudo, levanta-se a hipótese de que era o real sentido para explicar tal comportamento, sobretudo para as que se mantinham com essa conduta ao longo da gravidez. Uma das gestantes chegou a revelar de forma indiferente que seu comportamento podia ser prejudicial para o bebê, mas não para ela.

“...Eu não como. Eu fico dois dias sem comer. Aí, é só café e cigarro. Pro neném eu sei que faz mal. Mas pra mim..." (G3; seis meses de gravidez).

Outros relatos também chamaram atenção. Inicialmente pareceu estranho que, mesmo não querendo engravidar, duas mulheres tenham se conformado com essa condição desde sua confirmação. Para elas, que vivenciaram histórias traumáticas de aborto anteriormente, o pavor de provocar esse ato foi muito maior que o medo de ter que enfrentar a gravidez e mais um filho, contribuindo para que assumissem o evento desde o início e, conseqüentemente, um comportamento alimentar considerado "bom" por elas.

A privação (material e emocional) a que as mulheres estavam submetidas impedia a escolha autônoma e reflexiva em favor da vida, podendo resultar tanto na interrupção da gravidez quanto no abandono das crianças após o parto. Esses atos normalmente não ficam imunes à dor física, moral e emocional por parte das mulheres que os cometem e sobre as quais a justiça e a sociedade imputam a culpa, sendo esse mais um fator de desconstrução e deterioração da mulher enquanto sujeito. A culpa socialmente imputada à mulher no que se refere à prática do aborto e ao abandono de crianças corrobora para que muitas desenvolvam estratégias arriscadas, quase nunca assumidas como tais, para alcançar esses objetivos. 


\section{Conclusão}

Neste estudo, a conexão de sentidos entre a condição de estar grávida e o ato de comer motivou distintas lógicas de comportamento alimentar.

A gravidez, sua história e os significados que pode adquirir precisam ser conhecidos e interpretados por profissionais e por mulheres, com intuito de possibilitar contatos mais positivos, propositivos e criativos, que possam resultar, sempre que necessário, em sua ressignificação e na tomada de decisões autônomas, o que certamente irá contribuir com melhores resultados no ciclo gravídico-puerperal. Para isso, a necessidade de uma abordagem interdisciplinar é evidente, mas não suficiente. Torna-se imprescindível a reformulação de protocolos, procedimentos e condutas na saúde que abram espaço para a fala das mulheres e que os profissionais se sintam preparados e seguros para agir.

\section{Resumo}

O objetivo deste estudo foi compreender os sentidos de aceitação atribuídos à gravidez e a influência deles no comportamento alimentar de gestantes que freqüentavam uma unidade de saúde, localizada em uma comunidade urbana de baixa renda, no Município do Rio de Janeiro, Brasil. Adotou-se a abordagem qualitativa, tomando-se a categoria analítica das representações sociais como aporte metodológico do estudo. A construção dos dados ocorreu por meio de entrevista semi-estruturada com gestantes adolescentes e adultas, em distintos períodos de gestação, primíparas ou multíparas. A interpretação das falas foi orientada pela perspectiva da hermenêutica de profundidade, utilizando como recurso técnico a análise temática. Duas categorias representacionais nuclearam o conjunto dos depoimentos, o "assumir ou não gravidez", que implicou distintos comportamentos alimentares. No primeiro caso, as mulheres podiam estar se alimentando de maneira adequada ou cometendo exageros alimentares. Já a "gravidez não assumida", segunda categoria, estava ligada à negação do ato de comer, temporariamente ou não, ao longo da gestação.

Gravidez; Comportamento Alimentar; Pesquisa Qualitativa
Quando a escuta dos reais problemas não é desenvolvida, diminui a possibilidade de compreensão da relação do sujeito/grupo social com a alimentação e seu estado de saúde e/ou momento fisiológico. Nestas situações, a constituição de outros suportes de apoio também pode se tornar inviável.

A capacidade de desenvolver uma escuta autêntica para compreender as demandas objetivas e subjetivas das mulheres grávidas que buscam as unidades de saúde implica uma prática verdadeiramente interessada com a promoção da vida.

Espera-se que esta investigação possa suscitar a reflexão crítica sobre intervenções nutricionais dirigidas às mulheres grávidas que tentam modificar comportamentos e impor regras e condutas alimentares sem distinguir os sujeitos e o evento que os acomete, desconhecendo os sentidos e motivos que balizam seus comportamentos.

\section{Colaboradores}

M. R. Baião realizou a coleta, análise, interpretação dos dados e redação do artigo. S. F. Deslandes participou da redação e revisão do texto para publicação. 


\section{Referências}

1. Mendonça EA. A construção cultural do nascimento e suas representações: o olhar da gestante na medicalização da gravidez e do parto [Tese de Doutorado]. Rio de Janeiro: Instituto Fernandes Figueira, Fundação Oswaldo Cruz; 2004.

2. Saunders C, Neves EQC, Accioly E. Recomendações nutricionais na gestação. In: Accioly E, Saunders C, Lacerda E, organizadoras. Nutrição em obstetrícia e pediatria. Rio de Janeiro: Editora Cultura Médica; 2005. p. 147-70.

3. Rocha DS, Netto MP, Priore SE, Lima NMM, Rosado LEFPL, Franceschini SCC. Estado nutricional e anemia ferropriva em gestantes: relação com o peso da criança ao nascer. Rev Nutr 2005; 18:481-9.

4. Andreto LM, Souza AI, Figueiroa JN, Cabral-FilhoJE. Fatores associados ao ganho ponderal excessivo em gestantes atendidas em um serviço público de pré-natal na cidade de Recife, Pernambuco, Brasil. Cad Saúde Pública 2006; 22:2401-9.

5. Melo ASO, Assunção PL, Gondim SSR, Carvalho DF, Amorim MMR, Benício MHA, et al. Estado nutricional materno, ganho de peso gestacional e peso ao nascer. Rev Bras Epidemiol 2007; 10:249-57.

6. Motta-Maués MA. Lugar de mulher: representações sobre sexos e práticas médicas na Amazônia (Itapuá/Pará). In: Minayo MCS, Alves PC, organizadores. Saúde e doença: um olhar antropológico. Rio de Janeiro: Editora Fiocruz; 1994. p. 113-25.

7. Paim HHS. Marcas no corpo: gravidez e maternidade em grupos populares. In: Duarte LFD, Leal OF, organizadores. Doença, sofrimento, perturbação: perspectivas etnográficas. Rio de Janeiro: Editora Fiocruz; 1998. p. 31-48.

8. Chamilco RAS. Práticas culturais das parteiras tradicionais no cuidado gravídico-puerperal: um estudo etnográfico [Tese de Doutorado]. Rio de Janeiro: Escola de Enfermagem Anna Nery, Universidade Federal do Rio de Janeiro; 2004.

9. Baião MR, Deslandes SF. Alimentação na gestação e puerpério. Rev Nutr 2006; 19:245-53.

10. Borges ZN. A construção social da doença: um estudo das representações sobre o transplante renal. In: Leal OF, organizadora. Corpo e significado: ensaios de antropologia social. Porto Alegre: Editora da Universidade Federal do Rio Grande do Sul; 2001. p. 357-71.

11. Weber M. Conceitos sociológicos fundamentais. In: Weber M, organizador. Economia e sociedade: fundamentos da sociologia compreensiva. Brasília: Editora da Universidade de Brasília; 1994. p. 3-35.

12. Silva AS. Entre a razão e o sentido: Durkheim, Weber e a teoria das ciências sociais. Porto: Edições Afrontamento; 1988.

13. Leal OF, Lewgoy B. Pessoa, aborto e contracepção. In: Leal OF, organizadora. Corpo e significado: ensaios de antropologia social. Porto Alegre: Editora da Universidade Federal do Rio Grande do Sul; 2001. p. 55-74.
14. Mauldon J, Delbanco S. Public perceptions about unplanned pregnancy. Fam Plann Perspect 1997; 29:25-9.

15. Pulley L, Klerman LV, Tang H, Baker BA. The extent of pregnancy mistiming and its association with maternal characteristics and behaviors and pregnancy outcomes. Perspect Sex Reprod Health 2002; 34:206-11.

16. Queiroz MS. Saúde e doença: um enfoque antropológico. Bauru: EDUSC; 2003.

17. Adam P, Herzlich C. Saúde, doença e suas interpretações culturais e sociais. In: Adam P, Herzlich C, organizadores. Sociologia da doença e da medicina. Bauru: EDUSC; 2001. p. 69-86.

18. Herzlich C. A problemática da representação social e sua utilidade no campo da doença. Physis (Rio J) 2005; 15 Suppl:57-70.

19. Alves PC, Rabelo MC. Repensando os estudos sobre representações e práticas em saúde/doença. In: Alves PC, Rabelo MC, organizadores. Antropologia da saúde: traçando identidades e explorando fronteiras. Rio de Janeiro: Editora Fiocruz/Editora Relumé Dumará; 1998. p. 107-21.

20. Poulain JP, Proença RPC. Reflexões metodológicas para o estudo das práticas alimentares. Rev Nutr 2003; 16:365-86.

21. Minayo MCS. O desafio do conhecimento: pesquisa qualitativa em saúde. São Paulo: Editora Hucitec/Rio de Janeiro: ABRASCO; 2007.

22. Amazarray MR, Machado PS, Oliveira VZ, Gomes WB. A experiência de assumir a gestação na adolescência: um estudo fenomenológico. Psicol Reflex Crit 1998; 11:431-40.

23. Zaluar A. A máquina e a revolta: as organizações populares e o significado da pobreza. São Paulo: Editora Brasiliense; 2000.

24. Thompson JB. Ideologia e cultura moderna: teoria social crítica na era dos meios de comunicação de massa. Petrópolis: Editora Vozes; 1995.

25. Bardin L. Análise de conteúdo. Lisboa: Edições 70; 1977.

26. Bauer MW. Análise de conteúdo clássica: uma revisão. In: Bauer MW, Gaskell G, organizadores. Pesquisa qualitativa com texto, imagem e som: um manual prático. Petrópolis: Editora Vozes; 2002. p. 189-217.

27. Bodstein R, Zancan L. Avaliação das ações de promoção da saúde em contextos de pobreza e vulnerabilidade social. In: Zancan L, Bodstein R, Marcondes WB, organizadores. Promoção da saúde como caminho para o desenvolvimento local: a experiência de Manguinhos-RJ. Rio de Janeiro: ABRASCO; 2002. p. 39-60.

28. Zancan L, Bodstein R. DLIS-Manguinhos como estratégia de promoção da saúde. Saúde em Foco 2002; (23):49-63.

29. Bourdieu P. A dominação masculina. Rio de Janeiro: Editora Bertrand Brasil; 2005. 
30. Hita MG. Identidade feminina e nervoso: crises e trajetórias. In: Alves PC, Rabelo MC, organizadores. Antropologia da saúde: traçando identidades e explorando fronteiras. Rio de Janeiro: Editora Fiocruz/Editora Relumé Dumará; 1998. p. 179-214.

31. Leal OF. Sangue, fertilidade e práticas contraceptivas. In: Leal OF, organizadora. Corpo e significado: ensaios de antropologia social. Porto Alegre: Editora da Universidade Federal do Rio Grande do Sul; 2001. p. 15-37.

32. Rito RVVF. Obesidade e gravidez: mulheres obesas e seus hábitos alimentares durante a gravidez [Dissertação de Mestrado]. Rio de Janeiro: Instituto Fernandes Figueira, Fundação Oswaldo Cruz; 2004.
33. Ferreira JES. Comportamentos de risco para transtornos alimentares em adolescentes de escolas públicas de Niterói - RJ [Dissertação de Mestrado]. Rio de Janeiro: Instituto de Nutrição Josué de Castro, Universidade Federal do Rio de Janeiro; 2006.

34. Monteiro MFG, Adesse L. Estimativas de aborto induzido no Brasil e grandes regiões (1992-2005). http: / / www.ipas.org.br/arquivos/ml2006.pdf (acessado em 20/Set/2007).

35. Brasil. Portaria no. 344/98. Aprova o regulamento técnico sobre substâncias e medicamentos sujeitos a controle especial. Diário Oficial da União 1998; 15 mai.

Recebido em 11/Out/2007

Versão final reapresentada em 24/Mar/2008

Aprovado em 08/Abr/2008 